\section{Penggunaan Geotextile Non Woven Pada Proyek Peningkatan Jalan Anjir Pasar-Marabahan}

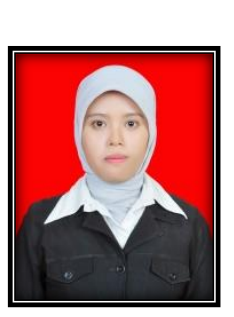

\section{Tria Dika Kumala, ST}

Tria Dika Kumala, mahasiswa Program Studi Program Profesi Insinyur (PS-PPI) Universitas Lambung Mangkurat Banjarmasin, dilahirkan di Surabaya pada tanggal 28 November 1986. Lulus S1 Teknik Sipil pada tahun 2008 dari Universitas Lambung Mangkurat Banjarmasin. Semenjak lulus kuliah bekerja di bidang konstruksi, tepatnya sebagai kontraktor.. buletinppi@ulm.ac.id
Ruas jalan Anjir Pasar-Marabahan merupakan jalan provinsi yang menghubungkan jalan nasional Banjarmasin-Palangkaraya dengan ibukota kabupaten Barito Kuala, Marabahan. Adapun lebar jalan existingnya adalah 4,50 $\mathrm{m}$. Dengan kegiatan peningkatan jalan, maka dilaksanakanlah pelebaran badan jalan pada ruas jalan tersebut. Pelebaran jalan dilaksanakan dengan menggunakan material yang propertiesnya lebih baik daripada tanah dasar. Kondisi tanah dasar yang merupakan tanah gambut memerlukan penanganan agar pekerjaan pelebaran pada tanah gambut tetap terjaga kualitasnya. Salah satu alternatif metodenya adalah dengan penggunaan Geotextile Non Woven. Geotextile non woven dapat berfungsi baik sebagai separator antara 2 (dua) lapisan material yang berbeda propertiesnya, sehingga tidak tercampur.

www.buletinppi.ulm.ac.id

\section{Pendahuluan}

Paket Peningkatan Jalan Anjir Pasar-Marabahan merupakan salah satu paket pekerjaan pada Dinas Pekerjaan Umum Pemerintah Provinsi Kalimantan Selatan. Lokasi pekerjaan adalah pada ruas jalan yang menghubungkan jalan Anjir Pasar (KM. BJM 18+900) menuju ibukota kabupaten Barito Kuala, Marabahan. Pekerjaan ini meliputi pekerjaan pelebaran badan jalan dari semula 4,50 meter menjadi 6,00 m. Sesuai dengan perencanaannya, konstruksi pelebaran badan jalan pada ruas jalan ini menggunakan perkuatan cerucuk galam dan geotextile non woven, serta menggunakan material timbunan pilihan, Lapis Pondasi Aggregat Kelas B dan Lapis Pondasi Aggregat Kelas A sebagai material pekerjaan pelebaran jalan. Pekerjaan pelebaran ini dilaksanakan diatas tanah gambut. Pekerjaan pelebaran badan jalannya menggunakan material yang sifat properties nya lebih baik dibandingkan tanah dasar. Untuk mendukung hal ini, maka digunakanlah geotextile non woven yang dapat berfungsi sebagai separator agar tanah dasar tidak bercampur dengan material perkerasan tambahan diatasnya. Dengan penggunaan geotextile non woven ini, diharapkan tidak terjadi pumping effect yang akan mudah merusak perkerasan jalan.

\section{Hasil Kerja}

\section{Geosintetik}

\subsection{Geotextile Non Woven}

Geotextile non woven merupakan salah satu jenis dari geosintetik. Berdasarkan sifat permeabilitasnya, geosintetik terbagi menjadi 2 jenis, yaitu : a. Geotextile, adalah geosintetik yang lolos air dan berasal dari bahan tekstil. Geotextile dibagi berdasarkan metode yang digunakan untuk menggabungkan filamen atau pita, sebagai bahannya, menjadi struktur lembaran. Jenis geotextile ada 2 (dua) jenis, yaitu geotextile teranyam (geotextile woven) dan geotextile tak teranyam (geotextile non woven).

b. Geomembran, adalah geosintetik yang kedap air, yang biasa digunakan sebagai penghalang zat cair.

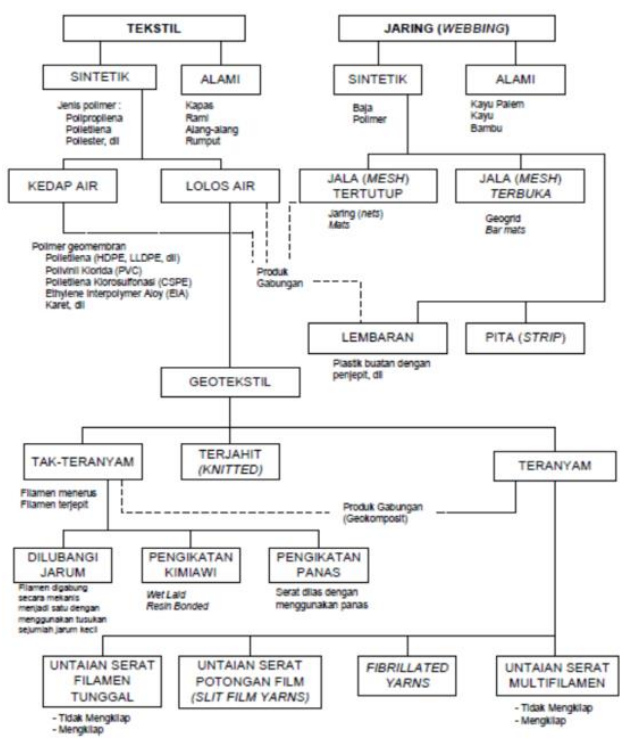

(Sumber : Hotlz dkk, 1998)

Gambar 1. Klasifikasi Geosintetik

Geotextile non woven adalah salah satu jenis geotextile yang berbentuk seperti karpet kain, lembaran dan tak beranyam (non woven). Pada umumnya terbuat dari bahan polimer polyesther (PET) atau Polypropylene 
(PP). pembuatan geotextile non woven dilakukan dengan teknologi canggih, dimana serat polimer didesak keluar dan dipuntir secara menerus, ditiup atau ditempatkan pada suatu sabuk berjalan. Kemudian massa polimer tersebut disatukan dengan proses mekanis dengan tusukan jarum-jarum kecil atau disatukan dengan panas dimana serat tersebut "dilas" oleh panas dan/atau tekanan pada titik kontak serat dengan massa tekstil tak teranyam. Karakteristik geotextile non woven ini mempunyai ketahanan terhadap kerusakan saat konstruksi, permeabilitas tinggi dan ketahanan terhadap UV. Adapun beberapa fungsi geotextile non woven adalah sebagai berikut :

a. Sebagai separator, karena memiliki kekuatan jebol (puncture resistance) yang tinggi untuk menjamin material tidak rusak pada saat pelaksanaan. Geotextile non woven dapat menjadi media pemisah antara dua lapisan material yang berbeda propertiesnya sehingga material yang propertiesnya jauh lebih baik tetap terjaga selama masa pelayanan.

b. Sebagai filter dan drainasi, karena memiliki bukaan pori yang relative kecil namun memiliki permeabilitas yang tinggi. Geotextile non woven berfungsi sebagai penahan butiran tanah yang baik, namun tetap memungkinkan aliran air tidak terganggu.

c. Sebagai perkuatan, karena geotextile non woven memiliki kuat tarik yang cukup memadai.

Beberapa contoh aplikasi geotextile non woven dapat digunakan untuk :

a. Konstruksi jalan

b. Stabilitasi tanah lunak

c. Konstruksi jalan rel

d. Filtrasi di belakang bronjong dan pemecah gelombang

e. Sistem drainase

f. Proteksi geomembran

Geotextile non woven dibuat dalam beberapa tipe, yang pada umumnya dapat dibedakan dari beberapa sifat teknisnya. Penentuan/pemilihan tipe geotextile non woven ini biasanya tergantung dari keadaan tanah dasar, fungsi serta beban yang telah direncanakan oleh konsultan perencana.

Pada proyek Peningkatan Jalan Anjir Pasar-Marabahan ini menggunakan geotextile non woven merk Bontec dengan tipe NW26 dari Geoforce Indonesia. Beberapa data teknis dari Geotextile Non Woven NW26 adalah sebagai berikut :

Tabel 1. Data Teknis Geotextile Non Woven Bontec NW26

\begin{tabular}{|l|l|c|c|}
\hline Properties & Unit & Test Method & NW26 \\
\hline Tensile strenght & $\mathrm{Kn} / \mathrm{m}$ & EN ISO & 26 \\
\hline
\end{tabular}

\begin{tabular}{|l|c|c|c|}
\hline $\begin{array}{l}\text { Elongation at } \\
\text { break MD }\end{array}$ & $\%$ & $\begin{array}{l}10319 \\
\text { EN ISO } \\
10319\end{array}$ & 75 \\
\hline $\begin{array}{l}\text { Elongation at } \\
\text { break CD }\end{array}$ & $\%$ & $\begin{array}{l}\text { EN ISO } \\
10319\end{array}$ & 55 \\
\hline $\begin{array}{l}\text { CBR Puncture } \\
\text { Resistance }\end{array}$ & $\mathrm{N}$ & $\begin{array}{l}\text { EN ISO } \\
12236\end{array}$ & 4350 \\
\hline Permeability & $\mathrm{m} / \mathrm{s}$ & $\begin{array}{l}\text { EN ISO } \\
11058\end{array}$ & $50 \times 10^{-3}$ \\
\hline $\begin{array}{l}\text { Characteristic } \\
\text { opening size }\end{array}$ & $\mu m$ & $\begin{array}{l}\text { EN ISO } \\
12956\end{array}$ & 70 \\
\hline $\begin{array}{l}\text { Thickness under } \\
\text { 2KPa }\end{array}$ & $\mathrm{mm}$ & EN ISO 9863 & 2,1 \\
\hline Weight & $\mathrm{g} / \mathrm{m}^{2}$ & EN 9864 & 325 \\
\hline Roll width & $\mathrm{m}$ & & 5,25 \\
\hline Roll lenght & $\mathrm{m}$ & & 100 \\
\hline
\end{tabular}

\subsection{Ketentuan Penyambungan untuk Geotextile}

Penyambungan geoxtile diperlukan untuk suatu aplikasi perkuatan yang memerlukan perkuatan menerus tanpa terputus. Teknik penyambungan yang paling banyak digunakan dan efisien untuk geotextile adalah teknik tumpang tindih dan penjahitan.

a. Teknik tumpang tindih

Menurut Pedoman Perencanaan dan Pelaksanaan perkuatan tanah dengan geosintetik No. 003/BM/2009 yang dikeluarkan oleh Direktur Jenderal Bina Marga Departemen Pekerjaan Umum, lebar tumpang tindih minimum direkomendasikan sebesar 0,3 $\mathrm{m}$, walaupun syarat tersebut dapat lebih besar untuk lokasi-lokasi khusus dan persyaratan konstruksi yang berbeda.

Sedangkan berdasarkan Spesifikasi Umum 2010 (Revisi 3) dari Direktur Jenderal Bina Marga Departemen Pekerjaan Umum, ketentuan tumpang tindih untuk geotextile dilaksanakan berdasarkan nilai CBR tanah dasarnya.

Tabel 2. Ketentuan Tumpang Tindih (overlap)

\begin{tabular}{|c|c|}
\hline Nilai CBR Tanah & $\begin{array}{c}\text { Tumpang Tindih } \\
\text { Minimum }\end{array}$ \\
\hline$>3$ & $300-450 \mathrm{~mm}$ \\
\hline $1-3$ & $0,6-1,0 \mathrm{~m}$ \\
\hline $0,5-1$ & $1 \mathrm{~m}$ atau dijahit \\
\hline Kurang dari 0,5 & Dijahit \\
\hline Semua ujung gulungan & $1 \mathrm{~m}$ atau dijahit \\
\hline
\end{tabular}

b. Teknik Penjahitan untuk Geotextile

Berdasarkan Pedoman Perencanaan dan Pelaksanaan perkuatan tanah dengan geosintetik No. 003/BM/2009 yang dikeluarkan oleh Direktur Jenderal Bina Marga Departemen Pekerjaan Umum, 
hal-hal yang perlu diperhatikan dalam pelaksanaan penjahitan geotextile ini adalah :

1) Jenis benang

Bahan dasar benang berdasarkan urutan kekuatan dan harga tertinggi adalah polietilena, polyester, atau polipropilena. Durabilitas benang hatus sesuai dengan persyaratan proyek.

2) Tegangan benang

Pada aplikasi di lapangan, benang sebaiknya ditegangkan dengan cukup kencang tetapi tidak sampai merobek geotextile.

3) Kerapihan jahitan

Biasanyan digunakan 200 jahitan sampai dengan 400 jahitan per meter untuk jenis geotextile ringan, dan hanya 150 jahitan sampai dengan 200 jahitan yang diperbolehkan untuk geotextile yang lebih berat

4) Jenis jahitan

- Tipe 101, dengan rantai jahitan tali tunggal

- Tipe 401, dengan rantai jahitan tali rangkap atau terkunci, untuk menghindari lepasnya jahitan (lihat Gambar 2.a)

5) Jumlah baris

Dua baris atau lebih dan sejajar untuk meningkatkan keamanan

6) Jenis penyambungan

Sambungan datar tipe SSa-2, bentuk J tipe SSn2, dan bentuk kupu-kupu tipe SSd-2 (lihat Gambar 2.b)
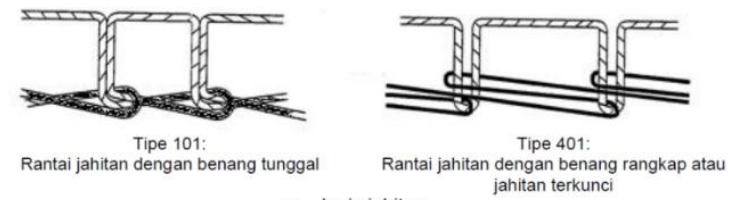
a. Jenis jahitan
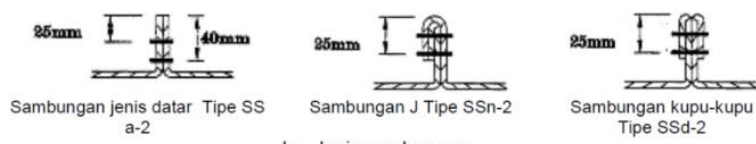

b. Jenis sambungan

(Sumber : Hotlz dkk, 1998)

Gambar 2. Jenis-jenis Jahitan dan Sambungan

\section{Desain Awal Pekerjaan}

Pekerjaan Peningkatan Jalan Anjir Pasar-Marabahan dilaksanakan sepanjang 2,5 km yang berlokasi di Desa Tumih, Kabupaten Barito Kuala, tepatnya mulai STA 12+000 sampai dengan STA $14+500$.

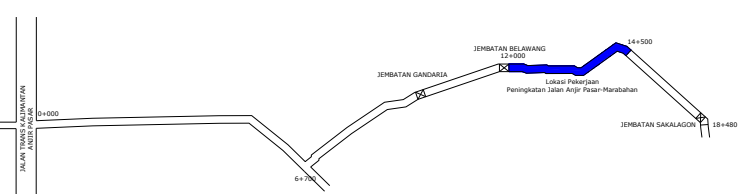

Gambar 3. Lokasi Pekerjaan Peningkatan Jalan Anjir PasarMarabahan

Pada pekerjaan Peningkatan Jalan Anjir Pasar-Marabahan, lebar aspal jalan existing yang semula 4,50 meter dilebarkan menjadi 6,00 meter.

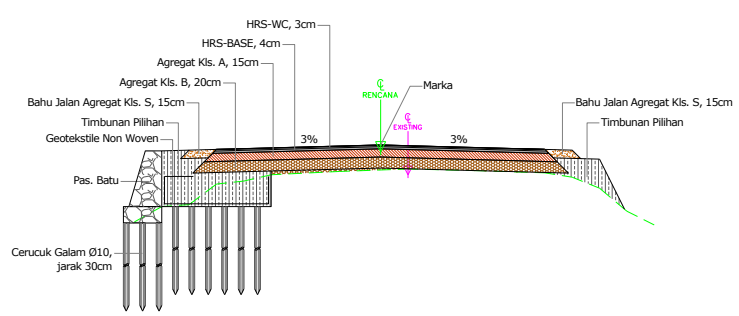

Gambar 4. Desain Penampang Melintang Pekerjaan Peningkatan Jalan Anjir Pasar-Marabahan

Adapun penanganan pekerjaan pelebaran jalannya dengan pekerjaan :

a. Pemancangan cerucuk galam $\varnothing 10 \mathrm{~cm}$, panjang $4 \mathrm{~m}$

b. Pasangan batu

c. Geotextile non woven

d. Timbunan pilihan

e. Lapis Pondasi Aggregat Kelas B, dengan tebal $20 \mathrm{~cm}$

f. Lapis Pondasi Aggregat Kelas, dengan tebal $15 \mathrm{~cm}$

g. HRS Base, dengan tebal $4 \mathrm{~cm}$

h. HRS WC, dengan tebal $3 \mathrm{~cm}$

i. Lapis Pondasi Aggregat Kelas A, dengan tebal $15 \mathrm{~cm}$

j. Marka Jalan Thermoplastik

\section{Penanganan Pekerjaan}

Berikut adalah dokumentasi visual kondisi 0\% pada pekerjaan Peningkatan Jalan Anjir Pasar-Marabahan sebelum pekerjaan dimulai :

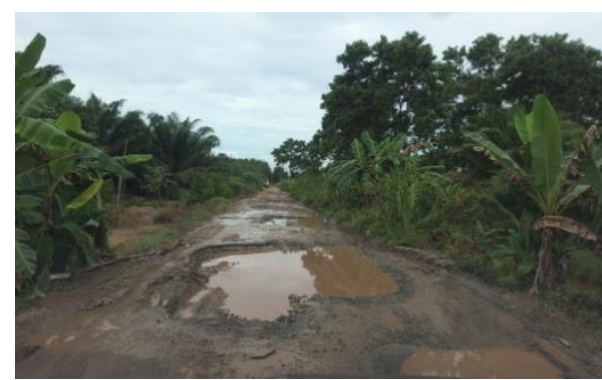

Gambar 5. Foto 0\% (STA 12+500)

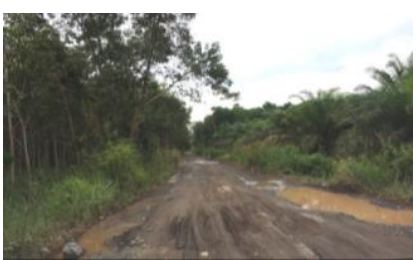


Untuk posisi pelebaran jalan, dilaksanakan dengan menggunakan geotextile non woven, yang berfungsi sebagai separator antara tanah dasar dan tanah timbunan pilihan. Teknik sambungan geotextile non woven yang digunakan adalah teknik penjahitan, dengan jenis jahitan Tipe 101 dan jenis sambungan Tipe SSa-2, menggunakan benang berbahan dasar polyester.

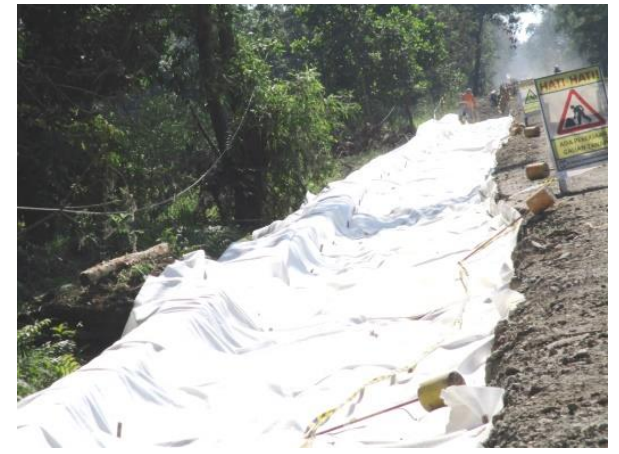

Gambar 7. Foto Pemasangan Geotextile Non Woven (STA $12+500)$

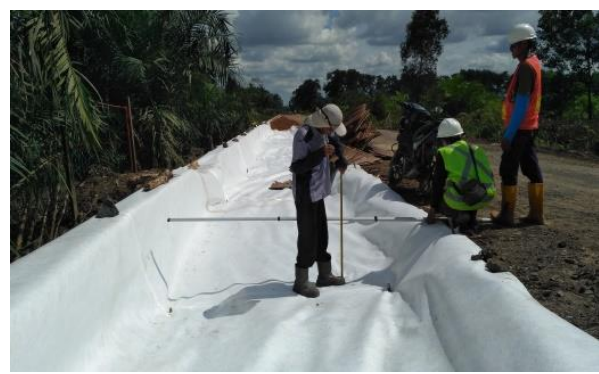

Gambar 8. Foto Pemasangan Geotextile Non Woven (STA $13+500)$

Tahapan selanjutnya pada lokasi pelebaran jalan tersebut adalah dengan memberikan material timbunan pilihan untuk lokasi yang telah dipasang geotextile non woven. Berikut adalah dokumentasi visualnya :

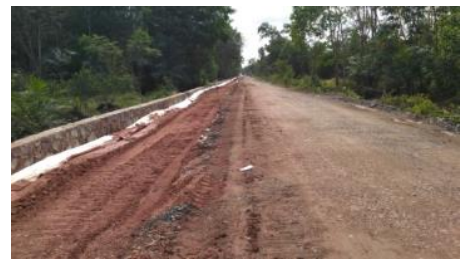

Gambar 9. Foto Pekerjaan Timbunan Pilihan (STA 12+500)

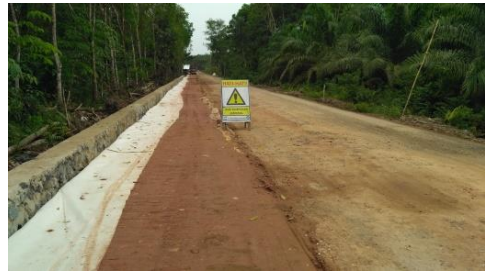

Gambar 10. Foto Pekerjaan Timbunan Pilihan (STA 13+500)

Tahapan pekerjaan perkerasan jalan berikutnya adalah dengan pelaksanaan pekerjaan Lapis Aggregat Kelas B dengan tebal $20 \mathrm{~cm}$, kemudian dilanjutkan dengan penghamparan Lapis Aggregat Kelas A dengan tebal $15 \mathrm{~cm}$. Setelah itu, dilanjutkan dengan pelapisan menggunakan Lataston Lapis Pondasi (HRS Base) dengan tebal 4,00 cm dan kemudian dilapis ulang menggunakan Lataston Lapis Aus (HRS WC) dengan tebal $3,00 \mathrm{~cm}$. Sebagai bahu jalan, selanjutnya dipasang Lapis Aggregat Kelas S pada sisi kanan dan kiri lapisan aspalnya.

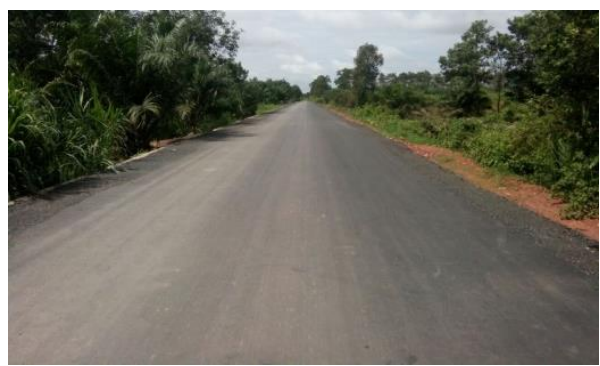

Gambar 11. Foto Kondisi Terakhir (STA 12+500)

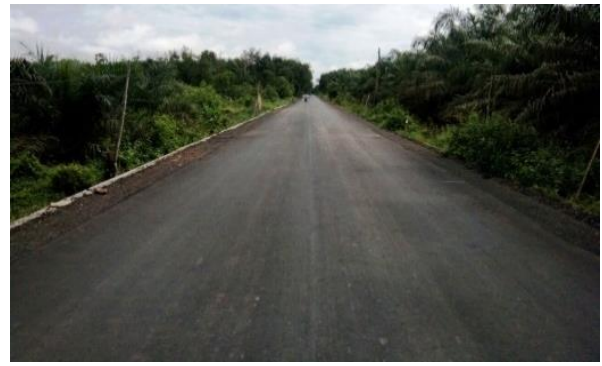

Gambar 12. Foto Kondisi Terakhir (STA 13+500)

\section{Kesimpulan}

Berdasarkan penggunaan Geotextile Non Woven pada proyek Peningkatan Jalan Anjir Pasar-Marabahan, dapat disimpulkan bahwa :

1. Penggunaan geotextile non woven pada tanah lunak berfungsi sebagai separator antara tanah dasar yang lunak dengan material tanah yang propertiesnya lebih baik, sehingga integritas dan tebal rencana struktur jalan dapat dipertahankan. 
2. Dalam pelaksanaan geotextile non woven, hal yang perlu diperhatikan adalah teknik penyambungan geotextile tersebut. Teknik penjahitan merupakan teknik penyambungan yang paling praktis dan ekonomis untuk diterapkan pada proyek ini.

\section{Ucapan Terimakasih}

Penulis mengucapkan terima kasih yang sebesarbesarnya kepada :

1. Suami, ibu dan anak-anak tercinta yang tiada hentinya memberikan kasih saying, doa dan dukungannya.

2. PT. Pandji Pratama Indonesia yang telah memberikan kepercayaan untuk memimpin proyek Peningkatan Jalan Anjir Pasar-Marabahan.

3. SKPD Dinas Pekerjaan Umum Provinsi Kalimantan Selatan atas kerjasama yang baik dalam menyelesaikan proyek Peningkatan Jalan Anjir Pasar-Marabahan.

4. Seluruh Dosen Program Studi Program Profesi Insinyur (PS-PPI) Universitas Lambung Mangkurat Banjarmasin.

5. Semua pihak yang telah turut membantu dalam penyusunan Buletin ini.

\section{Referensi}

1. Pusat Penelitian dan Pengembangan Jalan dan Jembatan, Badan Penelitian dan Pengembangan, Departemen Pekerjaan Umum. 2009. Pedoman Konstruksi dan Bangunan Perencanaan dan Pelaksanaan perkuatan tanah dengan geosintetik. Jakarta

2. Direktorat Jenderal Bina Marga Kementerian Pekerjaan Umum. Spesifikasi Umum 2010 (Revisi 3) : 3-46 